\title{
The effects of natural weathering exposure on the properties of pultruded natural fibre reinforced unsaturated polyester composites
}

\author{
M. H. Affzan, H. M. Akil, Z. A. M. Ishak \& A. A. Bakar \\ School of Materials and Mineral Resources Engineering, \\ Universiti Sains Malaysia, Malaysia
}

\begin{abstract}
Due to the demand for green technology, the development of fibre reinforced composites has built-up an interest in finding out new and reliable composites. The natural fibre reinforced composites produced by the pultrusion technique may eventually replace the conventional fibre composite production technique used today. In considering outdoor application, experiments have been performed to study the effects of weathering exposure on pultruded natural fibre reinforced composites. Kenaf fibre reinforced composites (KFRC) were produced using the pultrusion technique at $70 \%$ fibre loading. The composites were then subjected to natural aging, which involved exposing specimens to an outdoor natural environment for a period of time. After a few weeks, the specimen showed some degradation and discolouring. Subsequently, compression and flexural tests were carried out with the aim of determining the mechanical properties after exposure. The decrease in the value of these properties was verified and discussed. The repeated process of sun-heating and the invasion of moisture from natural atmosphere such as rain and dew everyday had led to debonding and weakening in the fibre-matrix interfaces of the composite.

Keywords: fibres, polymer-matrix composites (PMCs), weathering exposure, pultrusion.
\end{abstract}

\section{Introduction}

Historically, natural fibres were used as reinforcement in composites long ago by the Egyptians. The first composite materials known was made with clay and 
natural bamboo straw to built walls in Egypt 3000 years ago. However, starting from $20^{\text {th }}$ century, modern composites such as glass fibre reinforced composites or simply called fibreglass, have been used to make boats and aircrafts in the 1930s (Taj et al. [1]).

Since the 1970s, the development of new fibres such as boron, aramid and carbon makes the application of composites wares widely increased. These hightech synthetic fibres had entered and dominated the composites market due to their superior mechanical and thermal properties (Hapuarachchi et al. [2]). But recently, the environmental legislation as well as consumer awareness of recyclability has opened a huge chance to make natural fibres once again appear as an ideal reinforcement as a replacement for those synthetic fibres. The emerging demand of green economy or technology throughout the past few years had shown how important it was to produce a new material with approximately the same properties as common materials used today.

Currently, many types of natural fibres are available and are continuously being studied to be used as reinforcement in polymer composite including kenaf, jute, rice husk, ramie, sisal, coir, hemp, pineapple leaf fibre and many more. Compared to traditional glass fibre, natural fibre has lots of acceptable advantages such as abundant availability of raw materials from renewable resources (Kim et al. [3]), low density, good specific strength and modulus, economical viability, reduced tool wear, enhanced energy recovery, reduced dermal and respiratory irritation and good biodegradability (Dhakal et al. [4]). However, natural fibre reinforced composites experience some disadvantages including incompatibility between the hydrophilic natural fibres and hydrophobic thermoplastic and thermoset matrices requiring appropriate use of physical and chemical treatments to enhanced the adhesion between fibre and the matrix (Gassan and Gutowski [5]).

Kenaf (Hibiscus cannabinus L.) has been used as a cordage crop to produce twine, rope and sackcloth (Edeerozey et al. [6]), but recently, the development of this fibre as a reinforcement in polymer composite materials is catching the attention among researchers. Various techniques and treatment have been used to improve the mechanical and physical properties of these natural fibres. This lignocellulosic natural fibre can be produced in direct roving forms, which make it easier to be used as raw materials in pultrusion technique. Pultrusion technique principally producing a constant and continuous cross-section shapes fibrereinforced polymer composite (Starr [7]).

The main concern of this study was to observe the effects of absorption of moisture to the pultruded KFRC when exposed to natural weathering and its effects towards the mechanical and physical properties. Basically, all polymer composites tend to absorb moisture in humid atmosphere which may lead to degradation of fibre-matrix interface region creating poor stress transfer efficiencies resulting in a reduction of mechanical and dimensional properties (Yang et al. [8]). Moisture diffusion in polymeric composites is known to be governed by three different mechanisms. The first involves diffusion of water molecules inside the micro gaps between polymer chains. The second involves capillary transport into the gaps and flaws at the interfaces between fibre and the 
matrix. The third involves transport of micro cracks in the matrix arising from the swelling of fibres (particularly in the case of natural fibre composites) (Hazizan et al. [9]).

This paper focused on development and evaluation of a pultruded KFRC. Standard half an inch diameter rod samples of KFRC produced by pultrusion technique had been used in this study. The samples were left to natural weather for a certain period of time and tests were conducted to evaluate the mechanical and physical properties.

\section{Experimental}

\subsection{Materials}

Kenaf fibre was in direct roving form and supplied by JUTEKO Bangladesh Pvt. Ltd. While the unsaturated polyester resin (Crystic P9901) for pultrusion grade was purchased from Rivertex Company, Malaysia. The applied unit for yarn count varies between the fibre types, but the standard unit is "tex" which is defined as mass per unit length $(\mathrm{g} / 1000 \mathrm{~m})$ of roving, tow, yarn or strand (ASTM D2260). Tex also specifies roving linear density (Madsen [10]).

\subsection{Preparation of pultruded composites}

KFRC was prepared using pultrusion technique. Unidirectional kenaf fibre strands were placed on a creel of bookcase-type shelves, which were equipped with roving guider to lead the strands to the resin bath. Roving guider was used to ensure the strands did not scrape across one another as this would generate considerable static and caused "fuzz-balls" to build up in the resin bath, raising its viscosity (Meyer [11]). The continuous natural fibres were first impregnated with pultrusion grade unsaturated polyester (USP) resin in the resin impregnation tank. The pulling device worked as a pulling mechanism to pull the impregnated natural fibre through the heated steel die. The pulling device drew the stock through the die and determined the production speed (William [12]). Curing process was carried out in a heated die, which was precisely machined to impart the final shape. Finally, a cut-off mechanism was carried out to cut the continuous pultruded composites into the desired length. The average diameter of all composites rod was $12.7 \mathrm{~mm}$ and the fibre content used for all the samples in this study was $70 \%$ by weight. The processing parameters are given in Table 1.

Table 1: $\quad$ Processing parameter of pultrusion technique on KFRC.

\begin{tabular}{|l|c|c|}
\hline \multicolumn{1}{|c|}{ Parameter } & $\begin{array}{c}\text { Pulling speed } \\
(\mathrm{mm} / \mathrm{min})\end{array}$ & $\begin{array}{c}\text { Curing temperature } \\
\text { range } \\
\left({ }^{\circ} \mathrm{C}\right)\end{array}$ \\
\hline KFRC & $195-210$ & $90-110$ \\
\hline
\end{tabular}




\subsection{Material characterization}

\subsubsection{Water absorption investigation}

Specimens produced by the pultrusion technique were cut into specific lengths and dried in an oven at $100^{\circ} \mathrm{C}$ for 24 hours to remove any moisture trapped inside. After measuring the dry weight of the specimens using an electronic balance accurate to $10^{-4} \mathrm{~g}$, the specimens were left out to the natural weathering exposure to study the behaviour of the composites towards moisture uptake. The weight change was monitored as a function of time until $4800 \mathrm{~h}$ (200 days). The moisture content, $M(t)$ absorbed by each specimen was calculated according to Tsai et al. [13]:

$$
M(t)=100\left(\frac{w_{t}-w_{0}}{w_{0}}\right)
$$

where $w_{o}$ is the dry weight and $w_{t}$ is the weight after being exposed to natural environment for several times.

The diffusion coefficient, $D$ is evaluated from the first term of Eq. 5.25 from the book The Mathematics of Diffusion (Crank [14]), which is:

$$
D=\pi\left(\frac{a}{4 M_{\infty}}\right)^{2}\left(\frac{M_{t}}{\sqrt{\mathrm{t}}}\right)^{2}
$$

where $a$ is the radius of the specimen and $M_{\infty}$ is the saturation level of water absorption which is assumed as the maximum moisture content $\left(M_{m}\right)$ absorbed by the specimen. The $D$ value is calculated by using the moisture content, $M_{t}$ at the certain time range, $t$ which only being applied only at the beginning stages of the diffusion. Time was chosen at a very early stage of moisture process, so that the weight change can still be measured to vary linearly with the square root of time.

\subsubsection{Flexural testing}

Flexural test was carried out using Instron 8802 according to the standard ASTM D4476-03. Specimens were cut into two parts so that the cross section of each part was smaller than a half-round section. The specimen length is 16 to 24 times its thickness or depth, with at least $20 \%$ of the support span to allow a minimum of $10 \%$ overhang at the supports. The crosshead speed for flexural test was set at $5 \mathrm{~mm} / \mathrm{min}$. Three specimens for each condition were used to obtain a satisfactory result.

\subsubsection{Compression testing}

Compression test was carried out using Instron 8802 in accordance to the standard ASTM D 695-02a. The diameter and length of the specimen were $12.7 \mathrm{~mm}$ and $25.4 \mathrm{~mm}$ respectively. The crosshead speed for flexural test was set at $1.5 \mathrm{~mm} / \mathrm{min}$. Three specimens for each condition were used to obtain a satisfactory result. 


\section{Results and discussions}

\subsection{Water absorption investigation}

Moisture uptakes or water absorption behaviour is the main concern of structural composite in various outdoor applications. Every composite system has a unique behaviour upon moisture uptakes characteristic which depends on several factors such as the content of the fibre, fibre orientation, environmental temperature, exposed surface area, permeability of fibre, void content, and hydrophilicity of each individual component (Nosbi et al. [15]). Figure 1 shows the percentage of moisture content absorbed by three different tex of KFRC specimens within 200 days exposure to natural weathering. The moisture content, M (\%) absorbed by each specimen was calculated as Equation (1) earlier.

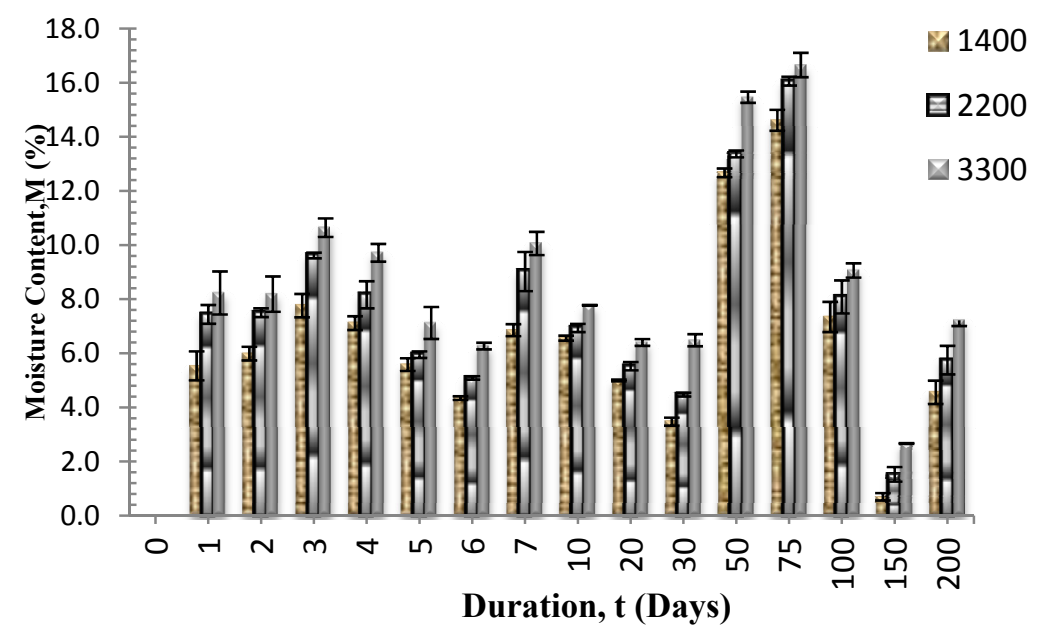

Figure 1: Moisture content absorbed after natural weathering exposure of KFRC.

Figure 1 shows the inconsistency of moisture content absorbed by KFRC from each day of data collection. The highest moisture content was taken on the $75^{\text {th }}$ day of exposure while the lowest was on day 150. This inconsistency occurred from the changes of weather with different amount of UV from sun and moistures from atmosphere every day.

However, this inconsistency shows the trend between the three tex of KFRC. For every data taken, KFRC 1400 tex has the lowest moisture content followed by KFRC 2200 tex and the highest was KFRC 3300 tex. After 200 days, the data can be simplified (as shown in Figure 2). 


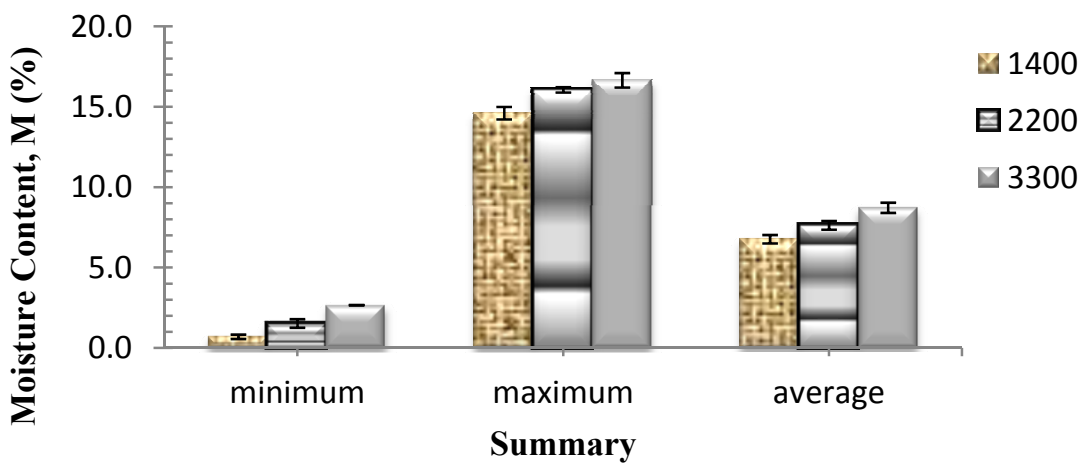

Figure 2: $\quad$ Summary of moisture content absorbed during natural weathering exposure of KFRC.

From Figure 2, the minimum, maximum and average percentage of moisture content within 200 days of exposure can clearly be seen. The minimum and maximum moisture content uptakes were $1-4 \%$ and $14-17 \%$ respectively of each tex. The average moisture content uptake for 200 days of exposure was ranged between 6 and $9 \%$.

The inconsistent results also came from the moisture diffusivity of KFRC for each tex. Diffusion coefficient (D) and maximum moisture content (Mm) for all tex of KFRC specimens was calculated using Equation (2) above and is summarized in Table 2.

Table 2: Maximum moisture content and diffusivity of KFRC for different tex.

\begin{tabular}{|l|c|c|c|}
\hline & 1400 tex & 2200 tex & 3300 tex \\
\hline $\begin{array}{l}\text { Maximum moisture } \\
\text { content, } \mathrm{M}_{\mathrm{m}}(\%)\end{array}$ & 14.6143 & 16.0630 & 16.6576 \\
\hline $\begin{array}{l}\text { Diffusion coefficient, } \\
\mathrm{D}\left(\mathrm{m}^{2} / \mathrm{s}\right)\end{array}$ & $2.7535 \times 10^{-13}$ & $3.2820 \times 10^{-13}$ & $4.0865 \times 10^{-13}$ \\
\hline
\end{tabular}

From the summarized value of $\mathrm{D}$ and $\mathrm{Mm}$ as shown on Table 2, it is clear that KFRC with 3300 tex has greater maximum moisture content and diffusion coefficient compared to 1400 and 2200 tex. This difference can be attributed to the exposed area of the fibre itself to the surroundings, which can make contact to the water molecules. The greater amount of fibre area exposed to the surrounding, the higher the tendency of absorbing water. However, the molecular and microstructure aspects such as polarity, the extent of crystallinity of polymers and the presence of residual hardeners or other water attractive species may also effect the moisture diffusion (Nosbi et al. [16]). 


\subsection{Flexural testing}

Variation of flexural strength and flexural modulus of KFRC after being exposed for 200 days to natural weathering are summarized in Figures 3 and 4 respectively. Each value represents an average data of three different tex of specimens and the flexural strength for polyester resin alone is $48 \mathrm{MPa}$ (Munikenche Gowda et al. [17]).

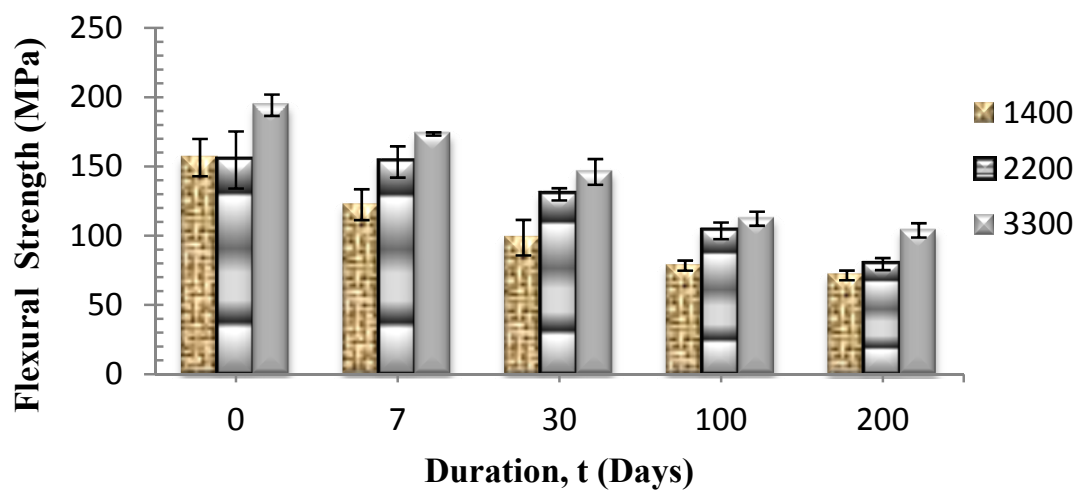

Figure 3: Flexural strength of KFRC after natural weathering exposure.

From Figures 3 and 4, the flexural strength and flexural modulus for all tex of KFRC was decrease with increasing time of exposure to natural weathering. But still, the KFRC with 3300 tex has the highest value among all for each day of data taken. It is assumed that the stress transfer between fibre and matrix interface is less effective due to the presence of moisture. Besides, moisture also causes the formation of hydrogen bonding between the cellulose fibre and water molecules (Nosbi et al. [16]).

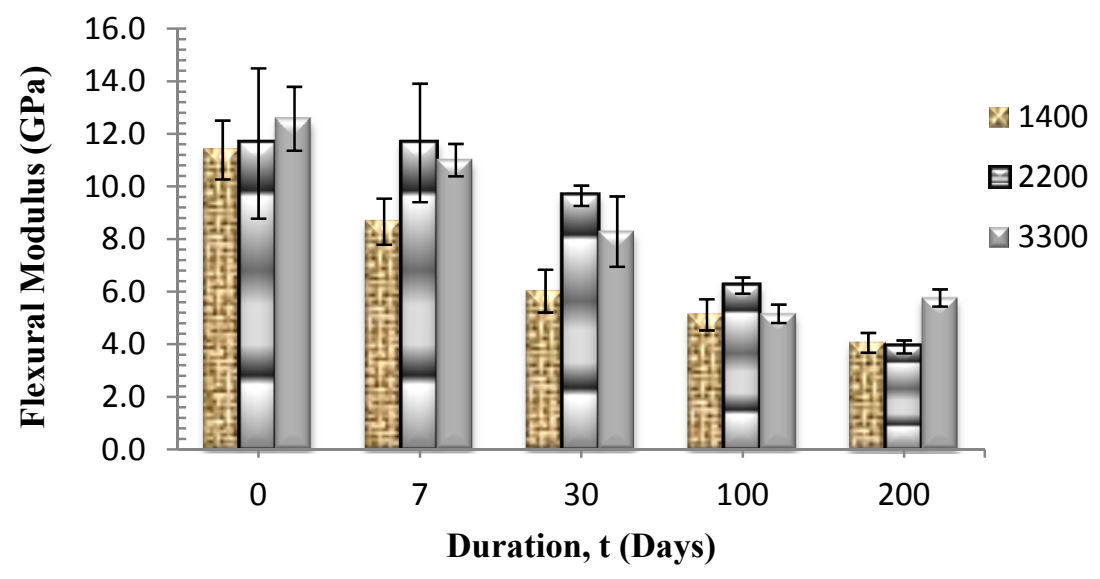

Figure 4: $\quad$ Flexural modulus of KFRC after natural weathering exposure. 


\subsection{Compression testing}

Figures 5 and represent the compressive strength and compressive modulus of KFRC after exposure of 200 days to natural weathering. Each value represents an average data of three different tex of specimens.

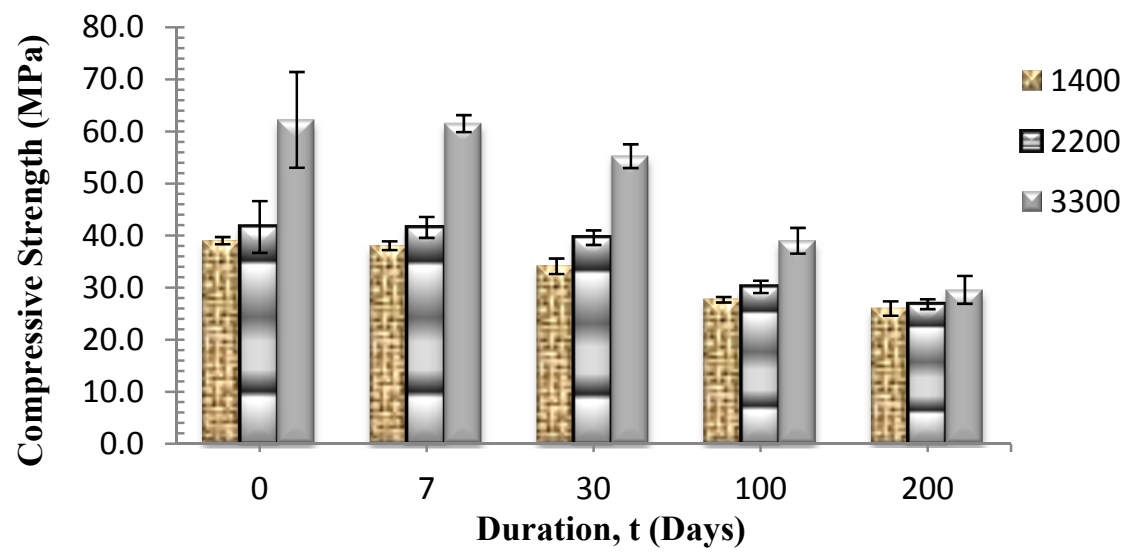

Figure 5: Compression strength of KFRC after natural weathering exposure.

As shown in Figure 5, the compression strength was decreased with increasing exposure time. This result was similar with the flexural properties as being discussed earlier. The compression strength for 3300 tex of KFRC showed reduction from $63 \mathrm{MPa}$ to $31 \mathrm{MPa}$ after 200 days of exposure. After 200 days of exposure, the compression strength for all different tex of KFRC seems to have almost the same value range from 29 to $31 \mathrm{MPa}$. However, in Figure 6, the inconsistent data was collected on the compression modulus in different tex of KFRC. The compressive modulus increased at the middle stage and finally drops at the end of exposure.

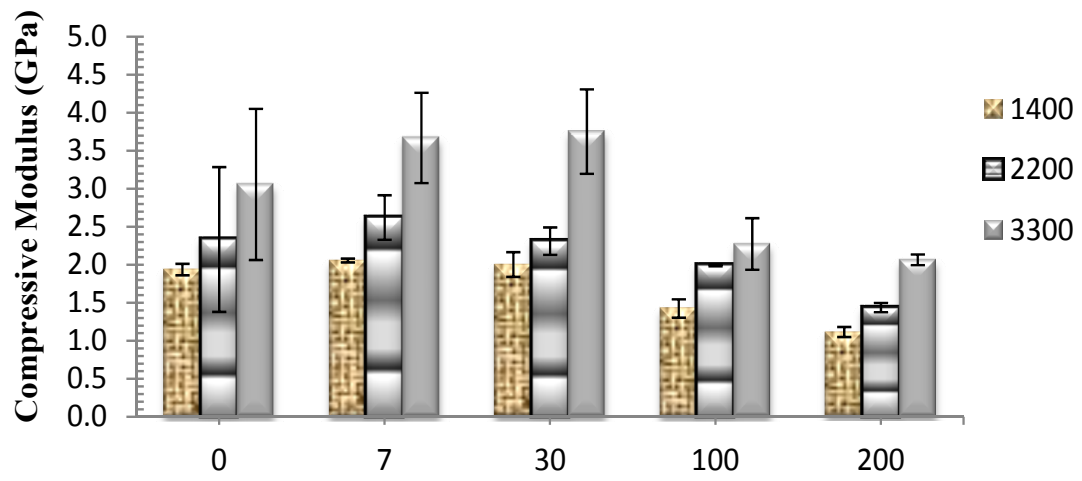

Duration, $t$ (Days)

Figure 6: Compression modulus of KFRC after natural weathering exposure. 
Both observations on flexural and compressive strength proved that moisture content can attack the fibre-matrix interface and significantly reducing the strength of the composites. Aside from the effect from moisture, micro cracks are also the sources of failure for the strength properties. Rapid changes of weather everyday caused the micro cracks to develop on the surface and the inside of the composites (Nosbi et al. [16]).

\section{Conclusion}

KFRC has been successfully produced using pultrusion method. From the study, a few conclusions can be drawn. Firstly, the natural weathering exposure study showed that KFRC could still be degraded throughout a period of time by several factors such as moisture and temperature changes. Prolonged exposure of KFRC to natural weathering may interfere the fibre matrix interface and causes degradation which significantly reduces the flexural and compression properties.

\section{Acknowledgements}

The authors are grateful to the School of Materials and Mineral Resources Engineering and Institute of Postgraduate Studies of Universiti Sains Malaysia (USM-814023 and 8640013) and Construction Industry Development Board of Malaysia (CIDB) for their assistance and contribution that has resulted in this article.

\section{References}

[1] Taj, S., M. Munawar, and S. Khan, Natural fiber-reinforced polymer composites. Proceedings Pakistan Academy of Sciences, 44(2): pp. 129, 2007.

[2] Hapuarachchi, T.D., et al., Fire retardancy of natural fibre reinforced sheet moulding compound. Applied Composite Materials, 14(4): pp. 251264, 2007.

[3] Kim, S., et al., Mechanical properties of polypropylene/natural fiber composites: Comparison of wood fiber and cotton fiber. Polymer Testing, 27(7): pp. 801-806, 2008.

[4] Dhakal, H., Z. Zhang, and M. Richardson, Effect of water absorption on the mechanical properties of hemp fibre reinforced unsaturated polyester composites. Composites Science and Technology, 67(78): pp. 1674-1683, 2007.

[5] Gassan, J. and V. Gutowski, Effects of corona discharge and UV treatment on the properties of jute fibre epoxy composites. Composites Science and Technology, 60(15): pp. 2857-2863, 2000.

[6] Edeerozey, A., et al., Chemical modification of kenaf fibers. Materials Letters, 61(10): pp.2023-2025, 2007.

[7] Starr, T., Pultrusion for engineers. Woodhead Publishing, 2000. 
[8] Yang, G., et al., Relation of modification and tensile properties of sisal fiber. Acta Sci Nat Uni Sunyatseni, 35: pp. 53-70, 1996.

[9] Hazizan, M.A., et al., Water absorption study on pultruded e-glass fibre reinforced unsaturated polyester composites. Advanced Composites Letters, 19(3): pp. 101 107, 2010.

[10] Madsen, B., Properties of Plant Fiber Yarn Polymer Composites: An Experimental Study. Technical University of Denmark, Department of Civil Engineering, Sektionen for Bygningsmaterialer og Geoteknik, 2004.

[11] Meyer, R., Handbook of pultrusion technology. Chapman and Hall New York, 1985.

[12] William Jr, D., Materials science and engineering: an introduction. John Wiley \& Sons, 2003.

[13] Tsai, Y., et al., Influence of hygrothermal environment on thermal and mechanical properties of carbon fiber/fiberglass hybrid composites. Composites Science and Technology, 69(3-4): pp. 432-437, 2009.

[14] Crank, J., The mathematics of diffusion. 2nd. Ed., Clarendon Press, Oxford, 1975.

[15] Nosbi, N., et al., Degradation of compressive properties of pultruded kenaf fiber reinforced composites after immersion in various solutions. Materials \& Design, 31(10): pp. 4960-4964, 2010.

[16] Nosbi, N., et al., Effect of Water Absorption on the Mechanical Properties of Pultruded Kenaf Fibre Reinforced Polyester Composites Advanced Composites Letters, 1(20): pp. 5-10, 2011.

[17] Munikenche Gowda, T., A. Naidu, and R. Chhaya, Some mechanical properties of untreated jute fabric-reinforced polyester composites. Composites Part A: applied science and manufacturing, 30(3): pp. 277284, 1999. 